\title{
Teaching Reading for Students with Intellectual Disabilities: A Systematic Review
}

\author{
Ghaleb Hamad Alnahdi ${ }^{1}$ \\ ${ }^{1}$ Special Education Department, College of Education, Prince Sattam bin Abdulaziz University, Alkharj, Saudi \\ Arabia \\ Correspondence: Ghaleb Hamad Alnahdi, Special Education Department, College of Education, Prince Sattam \\ bin Abdulaziz University, Alkharj, Saudi Arabia. E-mail: g.alnahdi@psau.edu.sa
}

Received: March 18, 2015 Accepted: April 30, 2015 Online Published: August 26, 2015

doi:10.5539/ies.v8n9p79 URL: http://dx.doi.org/10.5539/ies.v8n9p79

\begin{abstract}
A systematic review of the literature related to instructional strategies to improve reading skills for students with intellectual disabilities was conducted. Studies reviewed were within three categories; early reading approaches, comprehensive approaches, and one method approach. It was concluded that students with intellectual disabilities are in need to receive very intense practice and instruction to improve their reading skills, and it should be provided explicitly, systematically, and consistently. Recommendations for future studies are discussed.
\end{abstract}

Keywords: intellectual disabilities, reading, literature review

\section{Introduction}

There is a significant need for effective intervention strategies to address academic problems in school-aged children (Shapiro, 2010). Educators agree upon the importance of teaching academic skills through effective strategies. The question is what the most effective instructional strategies and methods to teach academics skills and knowledge to students are, and, more particularly, what methods have proven their effectiveness when used with students with intellectual disabilities, which is the main focus in this paper.

The ability to read is one of the most significant requirements for academic success (Thomas, 1996). Students' ability to read sometimes reflects their level of knowledge acquisition and skills; students with poor reading skills have more difficulty in school. Even more important, limited reading ability hinders the student from having a normal standard of life, and that can be a great disadvantage to them in finding vocational opportunities, for instance.

Reading, in general, and reading comprehension in particular, is strongly correlated with intelligence quotient level (IQ) (Bransford, Brown, Cocking, Donovan, \& Pellegrino, 2000). According to the American Association of Intellectual and Developmental Disabilities (AAIDD), IQ levels for students with intellectual disabilities are significantly lower than those of their typically developed peers, this low level in IQ clarifies the link with the difficulties they encounter during the process of learning to read. Reading is a complex task (Thomas, 1996), which makes learning to read a difficult process for students with intellectual disabilities.

Intellectual disability, in this paper, refers to "significant limitations both in intellectual functioning and in adaptive behavior, which covers many everyday social and practical skills. This disability originates before the age of 18 (AAIDD, 2010, p. 1)". This term "intellectual disability" is used interchangeably throughout this paper with significant cognitive disabilities and students with low IQs based on which term has been used in the study under review.

Allor, Mathes, Champlin, and Cheatham (2009) believe that instructional strategies or interventions that worked effectively with students who have high IQs will show effectiveness with students with low IQs. As it stated, "the curriculum and techniques that are effective for students with much higher IQs are also effective for students like Jacob, Carl, and Rachel [their IQs 44, 55, and 63]" (p. 364). However, not all instructional strategies or interventions that worked with students without disabilities can have the same effectiveness with students with intellectual disabilities because of the special characteristics of students with intellectual disabilities. In general, people with intellectual disabilities are less efficient at learning compared to other people 
without disabilities. This limitation in learning efficiency is consistent with overall IQ level for students with intellectual disabilities (Council of Exceptional Children [CEC], 2011).

Although instructors encounter many difficulties teaching students with intellectual disabilities how to read, and more challengingly reading comprehension, there are some instructional interventions that have been proven by many studies to be effective in helping students with intellectual disabilities improve their reading performance.

Thomas (1996) divided teaching reading for students with intellectual disabilities into three traditional types of instruction:

- Developmental reading: this type of reading instruction includes the mechanics of reading and reading comprehension.

- Functional reading: in this type of reading instruction, the main focus is on how students can use their reading ability, even if it is limited, to obtain necessary information to solve problems and complete their daily activities (Thomas, 1996).

- Remedial reading: this type of reading instruction is appropriate for students who still perform two or more years below their grade level. These programs are not always appropriate for students with intellectual disabilities because they require reading abilities very close to those of the average students, which can be challenging for students with intellectual disabilities.

However, Polloway, Patton, and Serna (2001) discussed the following three general approaches to teaching reading to students with disabilities:

- Language Experience Approach (LEA): an alternative to basal series and encourages students to verbalize their experiences and thoughts.

- Whole Language Approach: reading instructional method with expansion of language experience approach.

- Basal Reading Approach: a curriculum used in the majority of elementary schools, which contains a number of stories and books written at different levels of difficulties.

The significant of this study is derived from the fact that limited information (Katims, 2000) and training (Allor et al., 2009) are typically provided in college courses focused on how to teach reading skills for students with intellectual disability. This study aims to illustrate practices and themes are emphasized in literature as an effective way to teach students with intellectual disabilities reading skills. By the end of this literature review we will be able to answer the main question: What are the approaches/instructional practices that have proven to be effective in helping students with intellectual disabilities improve their reading skills?

\section{Method}

Academic search complete and ERIC were searched for articles published after 2000 that examined an intervention or strategy for teach reading for students with intellectual disabilities. The criteria for including studies in this literature review were two; first is examining intervention or strategy to improve reading skills or sub-reading skill; second is that participants in the study or part of them were students with intellectual disabilities. Nine studies were designed as experimental with two groups; treatment and control group. Single subject research designs were utilized for five studies. One study used a descriptive design with hierarchical regression analysis of the data, and one study covered 128 studies as intensive literature review. Three hundred and ninety four students with intellectual disabilities were included in these studies.

Table 1. Summary of the studies

\begin{tabular}{|c|c|c|}
\hline Research Design & Studies & $\begin{array}{c}\text { \# of } \\
\text { participants }\end{array}$ \\
\hline \multirow{4}{*}{$\begin{array}{l}\text { Experimental study with two } \\
\text { (control and treatment group) }\end{array}$} & $\begin{array}{l}\text { Allor, Mathes, Roberts, Cheatham, and } \\
\text { Champlin (2010) }\end{array}$ & 59 \\
\hline & Van, Nakken, Nicolay, and Van Houten (2007) & 38 \\
\hline & $\begin{array}{l}\text { Browder, Ahlgrim-Delzell, Courtade, Gibbs, } \\
\text { and Flowers (2008) }\end{array}$ & 23 \\
\hline & $\begin{array}{l}\text { Allor, Mathes, Roberts, Jones, and Champlin } \\
\text { (2010) }\end{array}$ & 28 \\
\hline
\end{tabular}


Conners, Rosenquist, Sligh, Atwell, and Kiser (2006)

Joseph and McCachran (2003)

Isikdogan and Kargin (2010)

Bijl, Alant, and Lloyd (2006)

Alfassi, Weiss, and Lifshitz (2009)

Allor, Mathes, Champlin, and Cheatham (2009)

Tucker-Cohen, Heller, Alberto, and Fredrick (2008)

Single subject design

Ruwe, McLaughlin, Derby, and Johnson (2011)

Didden, Graaff, Nelemans, Vooren, and Lancioni (2006)

Flores and Ganz (2009)

Wise, Sevcik, Romski, and Morris (2010)

Descriptive study

Browder, Wakeman, Spooner, Ahlgrim-Delzell, Literature review and Algozzine (2006)

\section{Result}

\subsection{Instructional strategies/interventions for Students with Intellectual Disabilities}

The hornbook or slate approach was the earliest methods of teaching reading in the United states until the early of 1900s (Thomas, 1996), which involved recognizing the alphabet and spelling of common words. In 1910, Gordon's system was started by grouping words with the same initial consonant and medial sounds, such as bag, bad, and bat. This system is known now as the phonetic system. In 1940, Kirk published the results from his project of intensive investigation about teaching reading; he suggested that a child should be exposed to and required to master 150 sight words as the first step in teaching reading, especially with slow learners as students with intellectual disabilities. Grossen and Carnine (1993) emphasized that the phonetic approach is effective with students with intellectual disabilities (Thomas, 1996).

One of the important studies that can provide us with an overview of the literature regarding teaching reading to students with intellectual disabilities is Browder, Wakeman, Spooner, Ahlgrim-Delzell, and Algozzine (2006) study. This study examined the results of a comprehensive review of 128 studies that focused on teaching reading to individuals with significant cognitive disabilities. After analyzing the 128 studies they found the following: 1) most of the studies targeted vocabulary, specifically, acquisition of sight words; 2 ) only $28 \%$ of the studies targeted fluency; 3) about a third of the studies targeted picture identification; 4) less than a third of the studies contained a measure of reading comprehension; 5) no studies adapting a longitudinal approach to literacy were found. One of the main findings in this comprehensive review was that special education teachers have highlighted the need for "intensive instruction [for students with significant cognitive disabilities] in order [for them] to learn to read (p. 393). However, it is worth noticing that Browder, Ahlgrim-Delzell, Courtade, Gibbs, and Flowers (2008) emphasized that although "students with significant developmental disabilities can gain early literacy skills through intensive instruction, much more research is needed to determine if these skills will lead to learning to read (p. 49)"

The next section of this paper reviews a body of literature that focused on instructional methods, strategies and interventions in order to investigate their effectiveness at improving reading skills for students with intellectual disabilities. It is divided to two main themes or approaches. The first approach includes studies that focused on subset skills such as sight word recognition. The second approach is a holistic approach that includes studies that have more a comprehensive approach like teaching comprehension, critical thinking, and phonologic awareness.

\subsection{The Comprehensive Approach}

Teaching reading for students with intellectual disabilities is a complex and difficult task, which leads many specialists in the field of special education to be advocate for more comprehensive approach to teach reading for students with intellectual disabilities. In this sense, Allor, Mathes, Roberts, Cheatham, and Champlin (2010) examined the effectiveness of comprehensive reading instruction on improving students with intellectual 
disabilities performance on standardized tests of reading. They assigned the participants (59) randomly to either treatment or control group; the participants IQs range from 40 to 69. The treatment group received comprehensive reading instruction on daily basis within small group from one to four students for 40 to 50 minutes per session. They collected the data through different types of tests such as: 1) The Comprehensive Test of Phonological Processing; 2) The Expressive Vocabulary Test; 3) Peabody Picture Vocabulary Test-III; 4) Test of Word Reading Efficiency. Factorial ANOVA have been used to analyze the collected data; pre-post test as the first factor and the groups as the second factor. They found that there were significant differences between the groups. Moreover, they conclude that students with intellectual disabilities need to have explicit, consistent, and comprehensive reading instruction for long period of time in order to learn basic reading skills.

Van, Nakken, Nicolay, and Van Houten (2007) investigated the effects of an intervention program that trains adults with mild intellectual disabilities in learning and applying text comprehension strategies (summarizing, questioning, and clarifying); the participants in this study were 38 adults (age range from 20 to 72 years). Participants' IQs were from 45 to 69 and they had been randomly assigned to either the experimental group or the control group. The intervention program was 15 weekly lessons for one hour each, and it contains strategies of summarizing, questioning, and clarifying, and the data collected through:1)Test for text comprehension strategies; 2)Tests for word-reading ability and general reading comprehension. They analyzed the collected data using MANOVA with Group (Experimental groups I and II), instruction condition strategy (Summarizing, Questioning, Clarifying, Predicting), text type (Narrative, Expository) and measurement (Pretest, Posttest), and they found that there were significant effects for the intervention program on adults' strategies of reading comprehension. They conclude that the used intervention program in this study provides a good starting point for adults with intellectual disabilities to improve their reading skills.

Browder, Ahlgrim-Delzell, Courtade, Gibbs, and Flowers (2008) examined the effectiveness of a comprehensive curriculum called the Early Literacy Skills Builder for students with significant developmental disabilities. This curriculum was designed to cover 12 sub-skills for reading comprehension for students with intellectual disabilities. The study conducted on 23 student (10 boys and 14 girls) participants who enrolled in self-contained special education classrooms, and they have been assigned randomly to either the treatment group (11 students) or to the control group (12 students). All students were pretested prior to start this study and they been tested by different type of measure to cover all 12 objectives that were part of the curriculum. Data were analyzed by conducting multi one way analysis of variances (ANOVAs) to determine differences between the treatment and the control group. The results showed statistically significant progress in the treatment group. Further, it was concluded that the comprehensive curriculum that been used in this study is effective in helping students with intellectual disabilities with their reading skills.

Allor, Mathes, Roberts, Jones, and Champlin (2010) examined the effectiveness of a comprehensive reading intervention (phonics-based and direct instruction reading program) in teaching early reading and language skills to students with moderate intellectual disabilities (IQs ranging from 40-55) through two years. The participants were 28 elementary students from 10 public schools in an urban school district and one urban private school who were randomly placed into either an intervention group that participated in daily, small group reading instruction delivered by research teachers or to a contrast group receiving typical special education. Students in the treatment condition received daily, comprehensive reading instruction in small groups of 1-4 students for approximately 40 minutes per session. They hired six certified special education teachers to provide instruction to students in this study.

Two types of measurement schemes were used to collect the data: 1) pretest and posttest; 2) continuous progress monitoring data every four weeks during the first year of the intervention and every six weeks during the second year. These measures focused on phonemic awareness, phonics, word recognition, comprehension, and oral language. Pretest data were analyzed using independent $t$-tests, and they found that no statistically significant differences between the treatment and contrast groups on any pretest measure. Also, independent $t$-tests was conducted to test score differences of the pretest and posttest measures to determine whether students in the treatment condition made greater gains than students in the contrast condition, and they found that there were statistically significant differences on all measures, including phonemic awareness, phonics, vocabulary, and comprehension. Lastly, they conclude that these findings demonstrated that students with moderate intellectual disabilities can learn basic reading skills if given consistent, explicit and comprehensive reading instruction across an extended period of time.

Allor, Mathes, Champlin, and Cheatham (2009) investigated the effective of five types of instructional (intervention) techniques to teach reading for students with intellectual disabilities. They conducted this study on three students (Ages 6, 8,9) with IQ $(44,55,63)$, who had been under these interventions for three years. The 1) 
techniques for teaching oral language and vocabulary; 2) techniques for teaching phonological awareness; 3 ) techniques for teaching phonics and word recognition; 4)techniques for teaching fluency; 5) techniques for teaching reading comprehension. They found that all five types of techniques were effective to some extent to teach students with intellectual disabilities to read. Finally, they concluded that the techniques that are effective for students with much higher IQs are also effective for students with mild and moderate intellectual disabilities.

Tucker-Cohen, Heller, Alberto, and Fredrick (2008) investigated the effectiveness of intervention strategy, they called it three-step decoding strategy and they used it with constant time delay as the instructional strategy, for teaching word reading and decoding to students with intellectual disabilities. They used a multiple probe design across students with the number of word sounded out as the dependent variable and the three-step decoding strategy as the independent variable. The participants were five students with intellectual disabilities (between 9 to 14 years old); three of them were in elementary school while the other two were in middle school. They used different types of assessment to collect the data through the multiple phases of their design (multiple probe design) and they started with Pre-intervention assessment in the baseline phase, and they continue collecting data during all phases: "(a) the attention-getting step, (b) the decoding step, and (c) the reading-the-word step" (p. 71) They found that three-step decoding strategy with constant time delay improved the students' skills in decoding and word reading.

\subsection{One Method Approach}

This part is about the literature that focused on one strategy or just one skill to improve reading skills for students with intellectual disabilities. Ruwe, McLaughlin, Derby, and Johnson (2011) examined the effectiveness of direct instruction strategy using flashcards to improve the sight word knowledge for students with intellectual disabilities. This study was conducted on three middle school students with intellectual disabilities who enrolled in a self-contained classroom as part of special education services. The data were collected by using Sight Word Knowledge Assessment in the baseline stage and all over the stages in the multiple baselines across sets that they adapted. It was found that the strategy used in this study (direct instruction) was effective in improving students with intellectual disabilities sight word knowledge. Finally, it was concluded that "employing a DI [direct instruction] flashcard procedure can increase important and functional academic skills for students with a wide-range of disabilities"(p. 254).

Didden, Graaff, Nelemans, Vooren, and Lancioni (2006) examined the effects of three training techniques to teach sight words to 13 students with intellectual disabilities, starting from their belief of the importance of sight word instruction as the gateway in a comprehensive reading instruction. This study was a multiple probe design, where students have been assessed according to the correct responses they can produce during probe sessions in the three stages: 1) word-alone stage (word without picture); 2) integrated-picture stage (word with integrated picture); 3) and picture-fading stage (integrated picture was faded out).The result showed that the word alone technique is the most effective technique comparing with the others techniques in this study.

Flores and Ganz (2009) examined the effectiveness of a direct instruction technique to improve reading comprehension for students with developmental disabilities (DD) and autism spectrum disorders (ASD). The researchers have chosen three strands for this study: picture analogies, induction, and deductions. Prior to any instruction, the researchers administered two curriculum-based assessments: (a) the placement test that accompanied the Direct Instruction Program, and (b) a running record that included comprehension questions following a passage that each student read orally. The data were collected for the four participants through a multiple probe design, where there were a baseline and treatments points, and they found that students' performance changed from the baseline level, which means there were an improvement. Further, they concluded that there is correlation between Direct Instruction and reading comprehension skills, which confirm the effectiveness of using direct instruction technique to teach reading for students with intellectual disabilities.

Conners, Rosenquist, Sligh, Atwell, and Kiser (2006) examined the effectiveness of phonological reading instruction for students with intellectual disabilities. The participants were forty students with intellectual disabilities, They were been chosen based on two criteria: 1) age between 7 and 12 years old; 2) IQ score less than 70 and substantial limitations in two or more in adaptive skill areas. The students in this study had been matched in pairs based on age, IQ, reading accuracy, phonemic awareness, and language comprehension. Then, randomly each pair split and one goes to the instruction group and the other goes to the control group. The data collected through pre-instruction assessment, instruction for the instruction group only, and a post-instruction assessment. Then they tested students individually by trained graduate and undergraduate student researchers for matching, assessing improvement, and predicting posttest outcome. Data were analyzed using factorial ANOVA $2 \times 2 \times 2$; factorial ANOVA was computed on the post-instruction sounding out tests, with repeated measures on 
the last two factors. The findings indicated that there was significant improvement in sounding out skill for the instruction group (treatment group) than the control group. Also the instruction group gained slightly more than the control group in sight word reading, and the instruction group as a whole performed significantly better than the control group on the post-instruction sounding out tests in predicting sounding out. Finally, it was concluded that students who completed 20 minutes lessons were better at sounding out instruction and transfer words and nonwords than children who did not have these lesson $\mathrm{s}$.

Wise, Sevcik, Romski, and Morris (2010) examined the correlation between phonological processing skills and word and nonword identification for students with mild intellectual disabilities in a reading intervention study. They assessed 80 elementary school students with mild intellectual disabilities ( 56 boys and 24 girls) by using a comprehensive set of reading-related measures such as: measures of receptive and expressive vocabulary, measures of phonological awareness, and measures of word and nonword identification. They analyzed the data from the comprehensive measures by a hierarchical regression technique, which allowed them to control for vocabulary knowledge and age. They found that phonological processing skills explained $31 \%$ of word identification performance and $29 \%$ of nonword identification performance, which means that phonological processing skills are the important skills for word and nonword identification. They conclude that phonological processing skills are correlated with reading performance for students with intellectual disabilities.

Joseph and McCachran (2003) compared the effectiveness of a technique called word sorts (word study phonics) on students 'word recognition, phonological awareness, and spelling. They compared students with intellectual disabilities with struggling young students without disabilities. In the first group there were eight students with intellectual disabilities and their IQ scores range from 55 to 76, while the second group was eight students and their IQ scores range from 85 to 106 . They administrated pretest and posttest for all students in the study using the Woodcock-Johnson Psycho-Educational Battery and the participants were in the classroom during the time of the study. Multivariate regression analysis was used to find out if there were statistically significant differences between groups when controlling for pretest result (MANCOVA).They found that there were no significant differences between the groups on posttest measures of word recognition, phonological awareness, and spelling when adjusting for pretest performance. However, it was concluded that some students with intellectual disabilities and other students without disabilities who have reading difficulties could benefit from implementing phonics instruction to improve their literacy performance.

In Turkey, Isikdogan and Kargin (2010) investigated the effectiveness of the story-map technique on reading comprehension for students with intellectual disabilities. They have chosen 14 students with intellectual disabilities who attended an elementary school and a special education center. They assigned seven students in the experimental group who were attending in an inclusive elementary school, and the control group was in a special education center. The data were collected via "Read-Aloud Test" and "Teacher Interview Form", along with pre-test and post-test for the experimental and the control group, and they found that the story-map technique was effective in improving reading comprehension for students with intellectual disabilities.

Bijl, Alant, and Lloyd (2006) compared two strategies of sight word instruction for students with intellectual disabilities, and they conducted on 33 participants. The participants had been matched based on receptive language skills, gender, and alphabet knowledge before they had been assigned to one of the three groups (modified orthography [MO], modified orthography association between the modification and the traditional orthography $[\mathrm{MO} / \mathrm{TO}]$, and the control group [TO]). They described the two strategies (modified orthography and the traditional orthography) as:

The modified [orthography] words were printed in lower case letter type Juniorhi, size 36 and enhanced/modified by incorporating a black line drawing (hand-drawn) into the orthography...[and] The traditional orthography words were printed in lower case letter type Juniorhi, size 36 and mounted on $10 \mathrm{~cm} \_10 \mathrm{~cm}$ flashcards" (p. 48).

The data were collected in two stages as pre-test and post-test to examine the differences in the effectiveness between treatment conditions. The findings indicated that there were no significant differences between students in the three groups in terms of word identification. However, they concluded that students with intellectual disabilities are able to learn sight words through any of the three strategies employed. There was no significant difference for word identification between the three groups.

Alfassi, Weiss, and Lifshitz (2009) investigated the effects of reciprocal teaching strategy on the reading literacy of students with intellectual disabilities. The participants were 35 students with intellectual disabilities (17 male students and 18 female students) aged from 15 to 21 years old and their IQ scores ranged from 40 to 69 , and they attended 24 sessions of reciprocal teaching strategy (experimental group) or the traditional methods of remedial 
literacy-skill acquisition- lessons (control group). The authors descried that the strategy used in this study was based "on the work of Vygotsky (1978), suggests a literacy programme-reciprocal teaching-in which students with intellectual disability are exposed to meaningful texts that include well-constructed and connected texts containing multiple sentences"(Alfassi, Weiss, \& Lifshitz, 2009, p. 301). The control group exposed to direct instruction of basic reading skills. Students in both groups been tested through four stages: 1) pretesting stage; 2) intervention stage; 3 ) maintenance post-intervention stage; 4) follow-up stage. Data were analyzed using $2 \times 2$ factorial MANOVA (groups $\times$ stages of intervention) and the findings indicated that there were significant differences between the two groups. It was concluded that reciprocal teaching is an effective technique that can be applied successfully in classrooms with students with intellectual disabilities.

\section{Discussion}

After reviewing the literature related to instructional strategies to improve reading skills for students with intellectual disabilities, it shows that there are many instructional strategies that have proven to be effective in helping students with intellectual disabilities improve their reading skills.

Special education teachers need to be aware of the effective instructional strategies to teach reading for students with intellectual disabilities, based on the literature, to overcome one of the reasons that there is low number of readers within students with intellectual disabilities because their teachers not exposed adequately to the effective strategies to teach students with intellectual disabilities (Allor et al., 2009). Moreover, expose special education teachers to the strategies that showed effectiveness with students without disabilities it can be also effective for students with intellectual disabilities (Allor, Mathes, Champlin, \& Cheatham, 2009). In the next part, we summarize the important characteristics of effective strategies to teach reading for students with intellectual disability.

\subsection{Explicit/Direct Instruction}

Explicit or direct instruction are emphasized so frequent in this literature review (e,g, Allore et al., 2010; Derby \& Johnson, 2011; Flores \& Ganz, 2009; Rupley, Blair, \& Nichols, 2009). Rupley et al. (2009) recommends that the six steps identified by Rosenshine and Stevens (1995) for teaching well-structured objectives could form the core of the direct/ explicit instruction. The six steps are the following:" 1) Review and check previous work; 2) present new material; 3) provide guided practice; 4) provide feedback and corrections; 5) provide independent practice; and 6) provide weekly and monthly reviews. (as cited in Rupley et al., 2009, p.126).”

\subsection{Long Period}

Teaching students with intellectual disabilities any skill, typically, require more time to be acquired comparing with students without disability. Reading is not an exception. A long time should be dedicated to teach students with intellectual disabilities to read or even for each sub-skill that essential for reading.

\subsection{Systematic}

Students with intellectual disability need to follow a systematic order of practices in order to enhance their abilities to absorb a chain of procedures or practices. A systematic teaching plan or intervention could help them to generalize, to some extent, what they learn in one practice to another one within the same context.

For instance, a "systematic phonics programs [is] a planned set of phonics elements are taught sequentially" (Ehri, Nunes, Stahl, \& Willows, 2001, p. 394). Therefore, special education teachers need to know what is come first as prerequisite sub-skills for different skills. This is taking us back to the one of main issue in the whole process of teaching students with intellectual disability, special education preparation pogrom need to prepare their students for such experience.

\subsection{Intellectual Disability's Level}

"Generalizations are difficult with such a diverse population as those with intellectual disabilities (Kauffman \& Hung, 2009, p. 455). Therefore, it is difficult to conclude one method as the best for all students with intellectual disabilities. Students with mild disability could benefit from approaches like the comprehensive one used by Van et al. (2007), Allore et al. (2010), or Browder et al. (2008). These approaches might not be suitable for students with moderate and sever intellectual disability. In addition, some advance skill such as fluency should not be a goal for students with intellectual disabilities in general, and particularly for those with moderate and sever intellectual disability.

To conclude, special education teachers need to remember that students with intellectual disabilities need to be exposed to extremely intense practice and instruction in order to learn to read (Allor, Champlin, Gifford, \& Mathes, 2010; Browder et al., 2008), which should be provided explicitly, systematically, and consistently(Allor 
et al., 2010).

Even though the comprehensive approach is recommended and demonstrated it is effectiveness with students with intellectual disabilities (Allor et al., 2009; Allor et al., 2010; Van et al., 2007), there many studies showed that focusing on one skill(reading sub-skills), such as sight word recognition or phonics, can be valuable for students with intellectual disabilities (Conners et al., 2006; Flores \& Ganz, 2009; Isikdogan \& Kargin, 2010; Joseph \& McCachran, 2003; Ruwe et al., 2011). Specifically for students with more than mild intellectual disability, in which focusing on one skill in a time appears more appropriate.

Lacking the use of technology seems like a very key element that is missing from the literature reviewed. Many technological tools could increase, to some extent, the possibilities for students with intellectual disabilities, and students with disabilities in general, to bypass some of the challenges with fewer difficulties. For instance, Patton and Roschelle (2008) argue that digital textbooks offer a better alternative than traditional textbooks because they can provide instant feedback, interactive representations, and the system of universal design for learning (UDL). A deeper examination of the use of technology to teach reading is warranted. Therefore, technology in other areas of learning could be explored.

Future research could explore various interventions or reading teaching strategy across different level of intellectual disability. In addition, special education preparation programs could be explored to examine whether there adequate number of courses and training on how to teach reading for students with intellectual disability.

In addition, teachers' perspectives in the field regarding best practices on teaching reading for students with intellectual disability could be studied. Especially, those who work with students with intellectual disability for many years. Results from such a study will add a different perspective to the literature on evaluating practicality or feasibility of a certain method. Some methods in some experimental studies will show a positive result, because of the additional support and attention which is not always available for teachers in the everyday context.

\section{References}

Alfassi, M., Weiss, I., \& Lifshitz, H. (2009). The efficacy of reciprocal teaching in fostering the reading literacy of students with intellectual disabilities. European Journal of Special Needs Education, 24(3), 291-305. http://dx.doi.org/10.1080/08856250903016854

Allor, J. H., Mathes, P. G., Champlin, T., \& Cheatham, J. P. (2009). Research-based techniques for teaching early reading skills to students with intellectual disabilities. Education and Training in Developmental Disabilities, 44(3), 356-366.

Allor, J. H., Mathes, P. G., Roberts, J. K., Cheatham, J. P., \& Champlin, T. M. (2010). Comprehensive reading instruction for students with intellectual disabilities: Findings from the first three years of a longitudinal study. Psychology in the Schools, 47(5), 445-466. http://dx.doi.org/10.1002/pits.20482

Allor, J. H., Mathes, P. G., Roberts, J. K., Jones, F. G., \& Champlin, T. M. (2010). Teaching students with moderate intellectual disabilities to read: An experimental examination of a comprehensive reading intervention. Education and Training in Autism and Developmental Disabilities, 45(1), 3-22.

Bijl, C. V. d., Alant, E., \& Lloyd, L. (2006). A comparison of two strategies of sight word instruction in children with mental disability. Research in Developmental Disabilities, 27(1), 43-55. http://dx.doi.org/10.1016/j.ridd.2004.12.001

Browder, D. M., Ahlgrim-Delzell, L., Courtade, G., Gibbs, S. L., \& Flowers, C. (2008). Evaluation of the effectiveness of an early literacy program for students with significant developmental disabilities. Exceptional Children, 75(1), 33-52.

Browder, D. M., Wakeman, S. Y., Spooner, F., Ahlgrim-Delzell, L., \& Algozzine, B. (2006). Research on reading instruction for individuals with significant cognitive disabilities. Exceptional children, 72(4), 392-408.

Conners, F. A., Rosenquist, C. J., Sligh, A. C., Atwell, J. A., \& Kiser, T. (2006). Phonological reading skills acquisition by children with mental retardation. Research in Developmental Disabilities: A Multidisciplinary Journal, 27(2), 121-137. http://dx.doi.org/10.1016/j.ridd.2004.11.015

Didden, R., de Graaff, S., Nelemans, M., Vooren, M., \& Lancioni, G. (2006). Teaching sight words to children with moderate to mild mental retardation: Comparison between instructional procedures. American Journal $\begin{array}{llll}\text { on Mental } & \text { Retardation, } & \text { 357-365. }\end{array}$ http://dx.doi.org/10.1352/0895-8017(2006)111[357:TSWTCW]2.0.CO;2 
Ehri, L. C., Nunes, S. R., Stahl, S. A., \& Willows, D. M. (2001). Systematic phonics instruction helps students learn to read: Evidence from the National Reading Panel's meta-analysis. Review of educational research, 71(3), 393-447. http://dx.doi.org/10.3102/00346543071003393

Flores, M. M., \& Ganz, J. B. (2009). Effects of direct instruction on the reading comprehension of students with autism and developmental disabilities. Education and Training in Developmental Disabilities, 44(1), 39-53.

Isikdogan, N., \& Kargin, T. (2010). Investigation of the effectiveness of the story-map method on reading comprehension skills among students with mental retardation. Educational Sciences: Theory and Practice, 10(3), 1509-1527

Joseph, L. M., \& McCachran, M. (2003). Comparison of a word study phonics technique between students with moderate to mild mental retardation and struggling readers without disabilities. Education and Training in Developmental Disabilities, 38(2), 192-199.

Katims, D. S. (2000). Literacy instruction for people with mental retardation: Historical highlights and contemporary analysis. Education and Training in Mental Retardation and Developmental Disabilities, 35(1), 3-15.

Kauffman, J. M., \& Hung, Li-Yu. (2009). Special education for intellectual disability: current trends and $\begin{array}{lllll}\text { perspectives. } \quad \text { Current } & \text { Opinion }\end{array}$ http://dx.doi.org/10.1097/YCO.0b013e32832eb5c3

Patton, C. M., \& Roschelle, J. (2008). Why the best math curriculum won't be a Textbook. Education Week, 24-32. Retrieved from EBSCOhost

Rosenshine, B., \& Stevens, R. (1995). Functions for teaching well-structured tasks. Journal of Educational Research, 88, 262-268. http://dx.doi.org/10.1080/00220671.1995.9941309

Rupley, W. H., Blair, T. R., \& Nichols, W. D. (2009). Effective reading instruction for struggling readers: The role of direct/explicit teaching. Reading \& Writing Quarterly, 25(2-3), 125-138. http://dx.doi.org/10.1080/10573560802683523

Ruwe, K., McLaughlin, T., Derby, K., \& Johnson, J. (2011). The multiple effects of direct instruction flashcards on sight word acquisition, passage reading, and errors for three middle school students with intellectual disabilities. Journal of Developmental \& Physical Disabilities, 23(3), 241-255. http://dx.doi.org/10.1007/s10882-010-9220-2

Tucker-Cohen, E., Heller, K. W., Alberto, P., \& Fredrick, L. D. (2008). Using a three-step decoding strategy with constant time delay to teach word reading to students with mild and moderate mental retardation. Focus on Autism and Other Developmental Disabilities, 23(2), 67-78. http://dx.doi.org/10.1177/1088357608314899

Van, d. B., Nakken, H., Nicolay, P. G., \& Van Houten, E. J. (2007). Adults with mild intellectual disabilities: Can their reading comprehension ability be improved? Journal of Intellectual Disability Research, 51(11), 835-849. http://dx.doi.org/10.1111/j.1365-2788.2006.00921.x

Wise, J. C., Sevcik, R. A., Romski, M., \& Morris, R. D. (2010). The relationship between phonological processing skills and word and nonword identification performance in children with mild intellectual disabilities. Research in Developmental Disabilities, 31(6), 1170-1175. http://dx.doi.org/10.1016/j.ridd.2010.08.004

\section{Copyrights}

Copyright for this article is retained by the author(s), with first publication rights granted to the journal.

This is an open-access article distributed under the terms and conditions of the Creative Commons Attribution license (http://creativecommons.org/licenses/by/3.0/). 